\title{
ANALYSES OF CORONARY GRAFT PATENCY AFTER APROTININ USE: RESULTS FROM THE INTERNATIONAL MULTICENTER APROTININ GRAFT PATENCY EXPERIENCE (IMAGE) TRIAL
}

\author{
Edwin L. Alderman, MD \\ Jerrold H. Levy, MD ${ }^{\mathrm{b}}$ \\ Jeffrey B. Rich, MD \\ Moshe Nili, MD \\ Bernardo Vidne, $\mathrm{MD}^{\mathrm{d}}$ \\ Hartzell Schaff, MD \\ Gideon Uretzky, MD \\ Gosta Pettersson, MD ${ }^{g}$ \\ Jens J. Thiis, MD \\ Charles B. Hantler, MD ${ }^{\mathrm{h}}$ \\ Bernard Chaitman, MD \\ Andrea Nadel, $\mathrm{PhD}^{\mathrm{j}}$ \\ On behalf of the IMAGE Investigators*
}

Objective: We examined the effects of aprotinin on graft patency, prevalence of myocardial infarction, and blood loss in patients undergoing primary coronary surgery with cardiopulmonary bypass. Methods: Patients from 13 international sites were randomized to receive intraoperative aprotinin $(n=436)$ or placebo $(n=434)$. Graft angiography was obtained a mean of $\mathbf{1 0 . 8}$ days after the operation. Electrocardiograms, cardiac enzymes, and blood loss and replacement were evaluated. Results: In 796 assessable patients, aprotinin reduced thoracic drainage volume by $43 \%(P<.0001)$ and requirement for red blood cell administration by $49 \%$ ( $P<.0001)$. Among 703 patients with assessable saphenous vein grafts, occlusions occurred in $15.4 \%$ of aprotinin-treated patients and $10.9 \%$ of patients receiving placebo $(P=.03)$. After we had adjusted for risk factors associated with vein graft occlusion, the aprotinin versus placebo risk ratio decreased from 1.7 to 1.05 (90\% confidence interval, 0.6 to 1.8). These factors included female gender, lack of prior aspirin therapy, small and poor distal vessel quality, and possibly use of aprotinin-treated blood as excised vein perfusate. At United States sites, patients had characteristics more favorable for graft patency, and occlusions occurred in $9.4 \%$ of the aprotinin group and $9.5 \%$ of the placebo group $(P=.72)$. At Danish and Israeli sites, where patients had more adverse characteristics, occlusions occurred in $23.0 \%$ of aprotinin- and $12.4 \%$ of placebo-treated patients $(P=.01)$. Aprotinin did not affect the occurrence of myocardial infarction (aprotinin: 2.9\%; placebo: $3.8 \%$ ) or mortality (aprotinin: 1.4\% ; placebo: 1.6\%). Conclusions: In this study, the probability of early vein graft occlusion was increased by aprotinin, but this outcome was promoted by multiple risk factors for graft occlusion. (J Thorac Cardiovasc Surg 1998;116:716-30)
$\mathrm{R}$ ecent studies have demonstrated that aprotinin, an inhibitor of certain serine proteinases ${ }^{1}$ administered during coronary surgery, significantly reduces postoperative blood loss and the need for allogeneic blood transfusion. ${ }^{2-10}$ One potential adverse effect of aprotinin could be postoperative graft occlusion. This has been studied

From the Division of Cardiovascular Medicine, Stanford University Medical Center, Stanford, Califa; The Department of Anesthesiology, Emory University School of Medicine, Atlanta, $\mathrm{Ga}^{\mathrm{b}}$; Sentara Hospital, Norfolk, $\mathrm{Va}^{\mathrm{c}}$; Division of Cardiothoracic Surgery, Beilinson Medical Center, Petach-Tivka, Israeld ${ }^{\mathrm{d}}$, the Mayo Clinic, Rochester, Minne; Carmel Medical Center, Haifa, Israelf; the University Hospital of Copenhagen, Denmark ${ }^{\mathrm{g}}$; the University of Texas Health Sciences Center, San Antonio, Tex ${ }^{\mathrm{h}}$; St Louis University Hospital, St Louis, Moi ; and the Department of Statistics and Data Systems, Bayer Corporation, West Haven, Conn. ${ }^{j}$

This report includes data from protocol D92-048 sponsored by Bayer Corporation, Pharmaceutical Division. E.L.A., J.H.L., J.R., M.N., B.V., H.S., G.U., G.P., J.J.T., C.B.H., and B.C. do not own stock or options in Bayer Corporation, but have received research support from Bayer Corporation. A.N. is an employee of Bayer Corporation. indirectly by electrocardiography (ECG) and by measuring enzyme levels in patients undergoing primary or repeat coronary artery bypass grafting $(\mathrm{CABG}))^{8,10,11}$ These studies documented a reduction in transfusion requirements and found no statistically significant increase in the prevalence of myocardial infarction in

Read at the Seventy-eighth Annual Meeting of The American Association for Thoracic Surgery, Boston, Mass, May 3-6, 1998.

Received for publication Jan. 26, 1998; revisions requested April 1, 1998; revisions received May 26, 1998; accepted for publication June 1, 1998.

Address for reprints: Edwin L. Alderman, MD, Professor of Medicine, Division of Cardiovascular Medicine, Stanford University Medical Center, CVRC-CV261, 300 Pasteur Dr, Stanford, CA 94305.

*A complete list of the IMAGE investigators is in the appendix.

Copyright (C) 1998 by Mosby, Inc.

$0022-5223 / 98 \$ 5.00+0 \quad \mathbf{1 2 / 6 / 9 2 1 4 5}$ 
patients treated with aprotinin. However, 1 other study reported an insignificant trend toward higher myocardial infarction rates in aprotinin-treated patients having a second $\mathrm{CABG}$ operation. ${ }^{7}$ Because enzyme and ECG criteria provide only indirect evidence of graft closure, the present study was designed with a sufficient sample size to investigate angiographically whether aprotinin has any adverse effect on graft patency in primary CABG operations. The study also investigated the prevalence of myocardial infarction and reassessed the effect of aprotinin on allogeneic transfusion requirements.

\section{Methods}

Patient selection. After institutional review committee approval and informed consent, patients who required elective myocardial revascularization and who did not require noncoronary procedures (eg, aneurysm resection or valve replacement) were studied. There was no upper age limit or gender restriction with the exception of known or suspected pregnancy.

Excluded patients were those with known or suspected allergy to aprotinin or radiographic contrast media or who had received an investigational drug within the preceding 30 days. Patients with any known bleeding disorder or hematologic abnormality that would require prophylactic use of drugs to decrease transfusion requirements were excluded, as were those who refused the use of allogeneic blood products, who had pre-donated autologous blood, or whose preoperative red blood cell (RBC) mass was so low that packed RBCs would be included in the prime fluid for cardiopulmonary bypass (CPB). Patients who had a previous median sternotomy, had diabetes mellitus with an elevated serum creatinine content, or had inadequate vascular access for postoperative angiography were also excluded.

Randomization was stratified on the basis of whether or not patients received aspirin therapy within the 5 days preceding the operation or a nonsteroidal anti-inflammatory drug (NSAID) within 3 serum half-lives before the operation (50\% in each group). The random code was generated in blocks within clinical center and stratum. At all times, patients and physicians were blinded as to randomization assignment.

Operative procedures. Anesthesia, $\mathrm{CPB}$, and postoperative intensive care procedures followed routine standards at each study site. The heparin loading dose for CPB was at least $350 \mathrm{IU} / \mathrm{kg}$, which was the total of that administered before aortic cannulation plus the heparin added to the prime volume of the CPB circuit. Additional heparin was given to maintain a kaolin-activated clotting time above 400 seconds and to maintain whole blood heparin levels of 2.7 units $/ \mathrm{mL}$ or more on the basis of a heparin-protamine titration test performed with the use of a heparin measurement system (Hepcon/HMS system, Medtronic HemoTec, Inc, Parker, Colo). Patients randomly assigned to the aprotinin group received a loading dose of 2,000,000 KIU of aprotinin, followed by continuous infusion at a rate of 500,000 KIU/h. In addition, 2,000,000 KIU of aprotinin was added to the CPB circuit prime.
At the termination of $\mathrm{CPB}$, packed RBCs were administered if the hematocrit value was less than $18 \%$. Postoperatively, homologous blood or packed RBCs were administered if the hematocrit value was less than $19 \%$. Additional transfusion was provided if warranted by the patient's condition. The use of additional hemostatic agents ( $\varepsilon$-aminocaproic acid or desmopressin) was permitted if postoperative bleeding could not be controlled by other means. After the operation, all patients received aspirin in a daily dose of $325 \mathrm{mg}$ with the first dose administered via nasogastric tube 6 hours after the operation.

Angiographic analysis. Angiography with non-ionic contrast material was performed shortly after the coronary operation. If serum creatinine levels were more than $1.9 \mathrm{mg} / \mathrm{dL}$ within 2 days of scheduled imaging, angiography was postponed. Angiographic readings using the same criteria were performed both at the Central Radiographic Laboratory at Stanford University and at each clinical site. Readers at the Central Radiographic Laboratory were blinded as to clinical site and their interpretations. In case of a discrepancy between the 2 readings, an independent reader adjudicated.

If grafts could not be identified by selective injection of graft stumps, then either aortography or selective injection of native coronary arteries (to identify collateral filling of occluded arteries) was used to assess graft patency. Because the particular adverse effect of aprotinin on graft patency being studied was presumed to be thrombotic, kinks, valves, and anastomotic stenoses were not considered as adverse events in either group. Total occlusions of grafts either at their origin or anywhere beyond were considered to be thrombotic events. In addition, a clearly evident thrombus within the graft, obstructing at least $50 \%$ of the luminal diameter, was interpreted as an occluding lesion (4 cases). Additional angiographic assessments included measurement of the graft diameter, the diameter of the distal vessel into which the graft was inserted, and the classification of the territorial distribution of the grafted distal native vessel as small, medium, or large. Other graft features considered in the final analysis included single graft versus sequential or Y grafts, the graft type (saphenous vein or internal thoracic artery), and location of the distal vessel grafted.

Detection of myocardial infarction. Blood samples for creatine kinase $(\mathrm{CK})$ and $\mathrm{CK}-\mathrm{MB}$ were collected before the operation, at the time of arrival in the postoperative care unit, $6,12,18$, and 24 hours after the operation, and on postoperative days 3, 5, and 7 or at hospital discharge. A standard 12lead ECG was acquired before the operation and on postoperative days 3, 5, and 7 or at hospital discharge. In patients having a suspected ischemic cardiac event outside the protocol window, an ECG was performed and enzyme levels associated with that event were examined.

Myocardial infarct events were determined on a blinded basis by the core ECG Laboratory at St Louis University Medical Center. All ECGs were classified according to the Minnesota code. ${ }^{12-15}$ The diagnosis of definite myocardial infarction was based on the following criteria: (1) the new development of a 2-step worsening in Q wave according to the Minnesota code, (2) the new development of persistent 
left bundle branch block patterns, or (3) the presence of acute necrosis at autopsy. The diagnosis of probable myocardial infarction was based on the presence of an abnormal postoperative cardiac enzyme profile (eg, CK-MB values > 120 units 6,12 , and 18 hours after the operation) or an abnormal profile associated with Minnesota code 1-step Q-wave worsening. The diagnosis of possible myocardial infarction was made when the cardiac enzyme profile was abnormal (persistent values > 100 units). The cardiac enzyme profile was considered nondiagnostic for myocardial infarction when all CKMB values were less than 100 units.

Data collection. Basic demographic and comprehensive clinical variables were collected, including the type and number of CABGs placed, the medications (including all doses of heparin and protamine with the time administered), blood or blood products administered, the hemoglobin/hematocrit measurements, activated clotting time and Hepcon heparinprotamine titrations during the operation, the study drug administration times, and emergency events. All adverse events were recorded both during and after the operation.

Thoracic drainage volume was recorded for the first 6 hours after patient transfer to the intensive care unit and then subsequently until removal of drains. The amounts of allogeneic whole blood, RBCs, fresh frozen plasma, platelets, and cryoprecipitate transfused were noted.

Statistical analyses. The primary outcome variable in this study was the percentage of patients with one or more occluded distal saphenous vein graft anastomoses determined by graft angiography. The study sample size was designed to detect a 50\% increase in the proportion of aprotinin-treated patients with saphenous vein graft occlusions versus placebo with $80 \%$ power using an expected placebo occlusion rate of $16 \%$ (1-tailed, $\alpha$.05). Confidence intervals at the $90 \%$ level were computed for the difference in by-patient saphenous vein graft occlusion rates. By means of the observed placebo closure rate and the confidence interval for the aprotininminus-placebo difference in rates, conditional confidence intervals for the aprotinin versus placebo odds ratio for closure also were computed.

For the primary, by-patient analysis, center and number of distal anastomoses were the a priori stratification factors. The by-graft covariate analyses included, but were not limited to, preoperative aspirin or NSAID usage, US versus European clinical sites (for regulatory purposes), and adherence or nonadherence to the concomitant heparin protocol. Stepwise logistic regression analysis of factors associated with saphenous vein graft occlusion considered each distal anastomosis separately. Stepwise regression analysis of factors contributing to vein graft occlusion included the patient-, laboratory-, operative-, graft-, and medication-related features listed in Table I. In addition, the regression analysis considered US versus European site, patient's date of operation within each center by tercile, tercile of interval between operation and angiography, heparin and protamine doses, and whether or not aprotinincontaining blood was used for vein graft preservation. Independent variables included demographic, clinical, laboratory, medication, and operative attributes. A $P$ value of .15 was used to identify those variables included in a model of saphe- nous vein graft risk for occlusion. Risk ratios for the number of graft occlusions and associated $90 \%$ confidence intervals were computed for all patient subgroups, comparing aprotinin treatment over placebo. The method of generalized estimating equations was explored to accommodate multiple observations within patients. The intra-patient correlations were found to be sufficiently small such that independence of graft observations was reasonable. Statistical analyses were conducted with the use of SAS programs (SAS Institute, Inc, Cary, NC).

\section{Results}

A total of 870 patients were randomized by clinical center by means of a computer-generated randomization code: 436 patients to the aprotinin group and 434 patients to the placebo group. The study included 10 US sites, which randomized $471(54 \%)$ of the patients (range 2 to 95 patients per site), and 3 sites within Israel and Denmark, which randomized 126 (14.5\%), $168(19.3 \%)$, and 105 (12.1\%) patients.

The mean age of all randomized patients was 62 years, $87 \%$ were male, $63 \%$ had severe angina, $28 \%$ had an ejection fraction below 0.50 , and $36 \%$ had received aspirin or an NSAID within 3 serum half-lives of the drug (usually 2 days) before the operation (Table I). The total number of grafts was 2928 with an average of 3.0 grafts per patient. An internal thoracic artery graft, usually to the left anterior descending artery, was inserted in $90 \%$ of patients. No significant differences were detected in any baseline characteristics among patients randomized to aprotinin and placebo groups. Table II outlines the reasons for exclusion from various analyses and provides the number of patients assessable for evaluating blood loss/blood replacement, saphenous vein graft occlusion, and myocardial infarction.

Blood loss and blood product replacement. Of the 870 randomized patients, 74 patients were excluded from this analysis of blood loss and blood product replacement because of additional intraoperative procedures $(n=14)$, preoperative blood transfusion $(n=3)$, other protocol deviations $(n=4)$, and confounding postoperative events $(n=53)$ (Table II). In regard to the latter, 37 postoperative events were related to bleeding, including 30 re-explorations and 7 episodes of gastrointestinal bleeding (Table II). Twenty-four of these 37 postoperative events occurred in the placebo group compared with 13 in the aprotinin group $\left(P=.07\right.$ by $\chi^{2}$ analysis).

Blood loss and blood product replacement results are summarized in Table III. The aprotinin-treated patients exhibited a $43 \%$ lower thoracic drainage volume and a 49\% lower requirement for allogeneic RBC administration (through day 12) when compared with the placebo group. In addition, the aprotinin-treated patients re- 
Table I. Characteristics of all patients and those included in the assessment of the saphenous vein grafts

\begin{tabular}{|c|c|c|c|c|c|c|}
\hline & & & \multicolumn{4}{|c|}{ Saphenous vein graft performed } \\
\hline & \multicolumn{2}{|c|}{ All study patients } & \multicolumn{2}{|c|}{$\begin{array}{l}\text { Angiography } \\
\text { not performed }\end{array}$} & \multicolumn{2}{|c|}{$\begin{array}{l}\text { Angiography } \\
\text { performed }\end{array}$} \\
\hline & Aprotinin & Placebo & All sites & All sites & US sites & $\begin{array}{l}\text { Danish and } \\
\text { Israeli sites }\end{array}$ \\
\hline Patient No. & 436 & 434 & 134 & $703 *$ & 381 & 322 \\
\hline Preop ASA/NSAID (\%) & 50.1 & 50.0 & 53.0 & 49.4 & 62.2 & 34.2 \\
\hline \multicolumn{7}{|l|}{ Clinical features } \\
\hline Age $(y r$, mean $\pm S D)$ & $61.8 \pm 9.1$ & $62.3 \pm 9.1$ & $64.3 \pm 9.7 \dagger$ & $61.8 \pm 9.0 \dagger$ & $61.6 \pm 9.4$ & $62.0 \pm 8.6$ \\
\hline Male $(\%)$ & 87.4 & 86.9 & 85.1 & 88.3 & 90.6 & 85.7 \\
\hline Weight $(\mathrm{kg}$, mean $\pm \mathrm{SD})$ & $81.7 \pm 14.1$ & $83.3 \pm 15.0$ & $82.3 \pm 14.9$ & $82.5 \pm 14.4$ & $85.9 \pm 15.0$ & $78.5 \pm 12.5$ \$ \\
\hline $\mathrm{BSA}(\mathrm{m}$, mean $\pm \mathrm{SD})$ & $1.94 \pm 1.8$ & $1.96 \pm 2.0$ & $1.95 \pm 2.0$ & $1.95 \pm 1.9$ & $2.00 \pm 1.9$ & $1.89 \pm 1.7 \ddagger$ \\
\hline NYHA class III-IV (\%) & 62.2 & 64.5 & 68.7 & 62.7 & 73.8 & $49.7 \neq$ \\
\hline $\mathrm{MI} \leq 30 \mathrm{~d}$ preop $(\%)$ & 11.7 & 14.3 & 16.4 & 12.7 & 19.2 & $4.97 \ddagger$ \\
\hline $\mathrm{LVEF} \leq 0.5(\%)$ & 29.2 & 26.3 & 25.6 & 28.8 & 28.1 & 29.6 \\
\hline \multicolumn{7}{|l|}{ Adjunctive drugs } \\
\hline $\begin{array}{l}\text { ASA within } 2 \text { days of operation } \\
(\%)\end{array}$ & 35.3 & 37.3 & 41.8 & 35.1 & 42.8 & $26.1 \neq$ \\
\hline $\begin{array}{l}\text { Total protamine }(\mathrm{mg} \\
\text { mean } \pm \mathrm{SD})\end{array}$ & $338 \pm 115$ & $337 \pm 10.5$ & $310 \pm 115 \dagger$ & $341 \pm 109 \dagger$ & $369 \pm 105$ & $309 \pm 104 \ddagger$ \\
\hline $\begin{array}{l}\text { Total heparin }(\mathrm{U} \\
\text { mean } \pm \mathrm{SD})\end{array}$ & $59,200 \pm 17,537$ & $59,627 \pm 15,571$ & $59,567 \pm 20,196$ & $59,410 \pm 16,002$ & $56,560 \pm 14,517$ & $62,782 \pm 17,015 \ddagger$ \\
\hline \multicolumn{7}{|l|}{ Laboratory analyses } \\
\hline Preop PTT $(\mathrm{s}$, mean \pm SD) & $31.6 \pm 14.3$ & $32.4 \pm 16.6$ & $34.0 \pm 22.0$ & $31.7 \pm 14.0$ & $36.1 \pm 16.2$ & $26.4 \pm 8.2$ \\
\hline Preop Hgb $(g / d L$, mean \pm SD) & $14.0 \pm 1.2$ & $14.0 \pm 1.3$ & $13.7 \pm 1.4 \dagger$ & $14.0 \pm 1.3 \dagger$ & $14.0 \pm 1.4$ & $14.0 \pm 1.3$ \\
\hline $\begin{array}{l}\text { Preop creatinine }(\mathrm{mg} / \mathrm{dL} \\
\text { mean } \pm \mathrm{SD})\end{array}$ & $1.13 \pm 0.23$ & $1.3 \pm 0.21$ & $1.15 \pm 0.24$ & $1.13 \pm 0.22$ & $1.11 \pm 0.24$ & $1.15 \pm 0.19$ \\
\hline \multicolumn{7}{|l|}{ Graft insertions (by patient) } \\
\hline Total/patient $($ mean $\pm \mathrm{SD})$ & $3.0 \pm 0.81$ & $3.0 \pm 0.9$ & $3.2 \pm 0.8$ & $3.1 \pm 0.8$ & $3.1 \pm 0.07$ & $3.1 \pm 0.8$ \\
\hline SVG/patient $($ mean $\pm \mathrm{SD})$ & $2.1 \pm 0.83$ & $2.1 \pm 0.9$ & $2.2 \pm 0.8$ & $2.1 \pm 0.8$ & $2.2 \pm 0.8$ & $2.1 \pm 0.8$ \\
\hline Y or sequential SVG (\%) & 24.1 & 22.7 & 26.1 & 23.9 & 31.2 & $15.2 \ddagger$ \\
\hline ITA graft $(\%)$ & 89.4 & 89.6 & 91.1 & 88.9 & 86.1 & 92.2 \\
\hline Total graft insertions (No.) & 1474 & 1454 & 321 & 1734 & 990 & 744 \\
\hline $\begin{array}{l}\text { Distal vessel } \leq 1.5 \mathrm{~mm} \\
(\% \text { of grafts })\end{array}$ & 54.1 & 51.8 & 59.4 & 56.5 & 54.3 & 59.4 \\
\hline \multicolumn{7}{|l|}{ Distal vessel quality: } \\
\hline Good (\% of grafts) & 46.0 & 46.4 & 44.7 & 45.6 & 56.5 & $31.3 \neq$ \\
\hline Fair/poor (\% of grafts) & 54.0 & 53.6 & 55.3 & 54.4 & 43.5 & $68.7 \neq$ \\
\hline \multicolumn{7}{|l|}{ Graft size: } \\
\hline Large (\% of grafts) & 12.6 & 14.0 & 16.7 & 14.8 & 11.8 & $18.7 \$$ \\
\hline Normal/small (\% of grafts) & 87.4 & 86.0 & 83.3 & 85.2 & 88.2 & $81.3 \ddagger$ \\
\hline
\end{tabular}

SVG, Saphenous vein graft; NSAID, nonsteroidal anti-inflammatory drug; $A S A$, acetylsalicylic acid (aspirin); BSA, body surface area; $L V E F$, left ventricular ejection fraction; PTT, partial thromboplastin time; $\mathrm{Hgb}$, hemoglobin.

*Thirty patients underwent angiography, but had no vein grafts.

$\dagger P<.01$ when comparing angiography and no-angiography groups.

$\ddagger P<.01$ when comparing US and European sites.

quired significantly fewer platelet transfusions, less fresh frozen plasma, less cryoprecipitate, and fewer additional hemostatic agents than did placebo recipients. No statistically significant differences were noted in the use of heparin or protamine administered during surgery between groups (Table III).

Angiographic results: Saphenous vein and internal thoracic artery grafts. Coronary arteriograms of adequate quality to assess saphenous vein graft patency were obtained a mean of 10.8 days after the operation (range 0-91 days; median 7 days), with $85 \%$ completed within 2 weeks of the operation. The clinical, laboratory, and operative features of the 703 patients in whom saphenous vein graft patency was assessable $(80.8 \%$ of all patients) did not differ markedly from those of the 134 not assessed (Table I). The non-assessed patients were slightly older, had less total protamine, and had lower preoperative hemoglobin values. 
Table II. Subject availability for outcome analysis

\begin{tabular}{|c|c|c|}
\hline & \multicolumn{2}{|c|}{ Patient No. } \\
\hline & Aprotinin & Placebo \\
\hline Randomized patients & 436 & 434 \\
\hline Analysis of blood loss and replacement & 401 & 395 \\
\hline $\begin{array}{l}\text { Exclusion for intraoperative protocol } \\
\text { deviation }\end{array}$ & 13 & 8 \\
\hline Random code unblinded & 1 & 2 \\
\hline Blood received preop or in prime fluid & 3 & 0 \\
\hline Additional intraop procedure & 8 & 6 \\
\hline Aprotinin discontinued & 1 & 0 \\
\hline Exclusion for confounding postop event & 22 & 31 \\
\hline Death within $6 \mathrm{~h}$ postop & 1 & 1 \\
\hline Re-exploration/surgical bleeding & 11 & 19 \\
\hline Additional postop surgical procedure & 8 & 6 \\
\hline Gastrointestinal bleeding & 2 & 5 \\
\hline $\begin{array}{l}\text { Angiographic analysis of SVG patency } \\
\text { by patient }\end{array}$ & 363 & 340 \\
\hline Exclusion: no SVG performed & 13 & 17 \\
\hline $\begin{array}{l}\text { Exclusion: death during hospitalization } \\
\text { for operation }\end{array}$ & 5 & 6 \\
\hline Exclusion: no postop angiography performed & d 49 & 68 \\
\hline Exclusion: not all SVGs assessable & 6 & 3 \\
\hline $\begin{array}{l}\text { Angiographic analysis of SVG patency } \\
\text { by distal anastomosis }\end{array}$ & 897 & 837 \\
\hline Exclusion: hospital death & 5 & 6 \\
\hline Exclusion: no postop angiography & 111 & 150 \\
\hline Exclusion: anastomosis not assessable & 9 & 5 \\
\hline $\begin{array}{l}\text { Angiographic analysis of ITA graft patency } \\
\text { by patient }\end{array}$ & 326 & 304 \\
\hline $\begin{array}{l}\text { Exclusion: no ITA graft with single } \\
\text { anastomosis performed }\end{array}$ & 55 & 54 \\
\hline $\begin{array}{l}\text { Exclusion: death during hospitalization for } \\
\text { operation }\end{array}$ & 6 & 4 \\
\hline Exclusion: no postop angiography performed & 43 & 66 \\
\hline Exclusion: ITA graft not assessable & 6 & 6 \\
\hline Analysis of myocardial infarction & 410 & 421 \\
\hline Exclusion: inadequate ECG data & 26 & 13 \\
\hline
\end{tabular}

$\overline{S V G \text {, Saphenous vein graft; } I T A \text {, internal thoracic artery; } E C G \text {, electrocardiogram. }}$

Of the 703 patients with assessable saphenous vein grafts, $15.4 \%$ of patients randomized to aprotinin had one or more occluded vein grafts compared with a $10.9 \%$ occlusion rate in patients randomized to placebo (Table IV). This $4.5 \%$ difference in graft occlusion rates had a $90 \%$ confidence interval of $1.3 \%$ to $9.6 \%$. The risk ratio overall was 1.5 (90\% CI, 1.1-2.1). These raw data demonstrated a significantly higher rate of graft occlusion for the aprotinin group $(P=.03)$.

A secondary analysis of distal vein graft anastomoses showed that $7.5 \%$ of distal anastomoses in the aprotinin group were occluded compared with $4.8 \%$ of anastomoses in the placebo group (Table IV). This $2.7 \%$ difference in occlusion rates corresponded to a risk ratio of 1.7 (90\% conditional CI, 1.2-2.1). No significant differences were seen in the very low occlusion rates (aprotinin $1.8 \%$; placebo $1.0 \% ; P=.32$ ) in the internal thoracic artery grafts.

Angiographic results: US patients compared with European patients. At Danish and Israeli sites, saphenous vein graft occlusion occurred in $23.0 \%$ of aprotinin-treated patients compared with $12.4 \%$ of comparable placebo-treated patients (risk ratio, 2.1; 90\% conditional CI, 1.3-2.9; Table IV). In contrast, at US sites vein graft occlusion rates were comparable at 9.4\% for aprotinin-treated patients and $9.5 \%$ for placebo-treated patients (risk ratio, 1.0; 90\% conditional CI, $0.5-1.8)$. At the Danish and Israeli sites, saphenous vein graft occlusion rates in both the aprotinin and placebo groups improved from the initial enrollment tercile to subsequent terciles (aprotinin, 34.5\%-17.0\%; placebo, $15.7 \%-10.9 \%$ ).

Because of these geographic differences in saphenous vein occlusion rates, patient characteristics listed in Table I were compared between US and European sites. Patients operated on at US sites weighed more and had a larger body surface area than those at the Danish and Israeli sites. US patients were more likely to have had a myocardial infarction within the preceding 30 days, had more severe angina, were more likely to have taken aspirin within 2 days before the operation, had longer preoperative partial thromboplastin times, and tended to have larger and better-quality distal vessels than the European patients (Table I).

Of the 13 surgical sites, 5 used heparinized and aprotinin-containing blood from the aortic cannulation site for flushing and preservation of the harvested vein. These 5 sites included the 3 Danish and Israeli sites (46\% of study patients) and 2 small US centers (9\% of study patients). At the remaining 7 US sites (45\% of study patients), non-blood containing perfusate was used. At 1 Israeli site during the initial third of patient enrollment, blood for vein flushing and preservation was obtained from the same central venous line into which the aprotinin bolus and infusion had been administered. At this site, the saphenous vein graft occlusion rate was $73 \%$ in aprotinin-treated patients during the first third of the study, which significantly exceeded the $11 \%$ occlusion rate in placebo-treated patients. After revision of procedures at this site, saphenous vein graft occlusions in aprotinin-treated patients decreased to $14 \%$ compared with $3 \%$ in placebo-treated patients for the remaining two thirds of the study.

Stepwise regression analysis of predictors of graft occlusion. Variables predictive of increased graft occlusion for aprotinin versus placebo were smaller distal vessel size, lower total protamine dose, smaller graft size, older age, lower ejection fraction, female gender, no aspirin within 2 days before the operation, 
Table III. Analysis of blood loss and replacement

\begin{tabular}{|c|c|c|c|}
\hline & Aprotinin $(n=401)$ & Placebo $(n=395)$ & $\mathrm{P}$ value \\
\hline \multicolumn{4}{|l|}{ Surgical factors } \\
\hline Duration of operation (h, mean $\pm \mathrm{SD}$ ) & $3.5 \pm 1.5$ & $3.6 \pm 1.4$ & .36 \\
\hline Total bypass time (min, mean \pm SD) & $93.2 \pm 53.8$ & $92.9 \pm 54.6$ & .89 \\
\hline Closure time (min, mean $\pm \mathrm{SD}$ ) & $46.4 \pm 32.94$ & $50.9 \pm 33.7$ & .001 \\
\hline Heparin during surgery $(\mathrm{U} / \mathrm{kg}$, mean $\pm \mathrm{SD})$ & $687 \pm 298$ & $687 \pm 302$ & .99 \\
\hline Protamine during surgery $(\mathrm{mg}$, mean $\pm \mathrm{SD})$ & $331 \pm 154$ & $328 \pm 157$ & 68 \\
\hline \multicolumn{4}{|l|}{ Blood loss } \\
\hline Total thoracic drainage $(\mathrm{mL}$, mean $\pm \mathrm{SD})$ & $664 \pm 1009$ & $1168 \pm 1022$ & $<.0001$ \\
\hline Postop drainage $-\mathrm{mL} /$ initial $6 \mathrm{~h}$, mean $\pm \mathrm{SD}$ ) & $228 \pm 459$ & $491 \pm 465$ & $<.0001$ \\
\hline Change in hemoglobin from hospital entry to discharge $(\mathrm{g} / \mathrm{dL}$, mean $\pm \mathrm{SD})$ & $-2.7 \pm 8.0$ & $-3.6 \pm 8.2$ & .003 \\
\hline Time in hospital $(\mathrm{d}$, mean $\pm \mathrm{SD})$ & $7.6 \pm 8.5$ & $7.8 \pm 8.6$ & .60 \\
\hline \multicolumn{4}{|l|}{ Donor replacement through day 12} \\
\hline Patients requiring any blood product (\%) & 40 & 58 & $<.0001$ \\
\hline Patients requiring donor RBCs (\%) & 38 & 54 & $<.0001$ \\
\hline All allogeneic blood/blood products required (U/patient, mean $\pm \mathrm{SD}$ ) & $1.1 \pm 2.2$ & $3.8 \pm 7.3$ & \\
\hline $5,50,95$ percentiles & $0,0,4.5$ & $0,2,18$ & $<.0001 *$ \\
\hline Packed RBCs (mL/patient, mean \pm SD) & $296 \pm 500$ & $575 \pm 790$ & \\
\hline $5,50,95$ percentiles & $0,0,1400$ & $0,300,2100$ & $<.0001 *$ \\
\hline Platelets (U/patient, mean \pm SD) & $0.1 \pm 1.1$ & $1.2 \pm 3.5$ & \\
\hline $5,50,95$ percentiles & $0,0,0$ & $0,0,10$ & $<.0001 *$ \\
\hline Fresh frozen plasma (U/patient, mean $\pm \mathrm{SD})$ & $0.2 \pm 0.8$ & $0.5 \pm 1.7$ & \\
\hline $5,50,95$ percentiles & $0,0,2$ & $0,0,4$ & $<.0001 *$ \\
\hline Cryoprecipitate (U/patient, mean $\pm \mathrm{SD}$ ) & $0 \pm 0.0$ & $0.4 \pm 2.1$ & \\
\hline $5,50,95$ percentiles & $0,0,0$ & $0,1,5$ & $<.0001 *$ \\
\hline \multicolumn{4}{|l|}{ Donor RBCs (U/patient) } \\
\hline All patients $($ mean \pm SD) & $0.8 \pm 1.3$ & $1.6 \pm 2.0$ & \\
\hline $5,50,95$ percentiles & $0,0,3$ & $0,1,5$ & $<.0001 *$ \\
\hline High-risk patients (mean \pm SD) & $0.9 \pm 1.3$ & $1.6 \pm 2.0$ & \\
\hline $5,50,95$ percentiles & $0,0,3.5$ & $0,1,6$ & $<.0001 *$ \\
\hline Low-risk patients (mean \pm SD) & $0.7 \pm 1.3$ & $1.6 \pm 2.1$ & \\
\hline $5,50,95$ percentiles & $0,0,3$ & $0,1,5$ & $<.0001 *$ \\
\hline
\end{tabular}

RBCs, Red blood cells.

*Data were analyzed nonparametrically with rank analysis of variance.

and lower quality distal vessels (Table V, column 1). These adverse predictors of graft occlusion were consistently more prevalent in the Danish and Israeli patients than in the US patients (Table I).

Table V summarizes the effect of patient- and graftrelated predictors of saphenous vein graft occlusion on graft occlusion associated with aprotinin versus placebo treatment. Saphenous vein grafts placed at Danish and Israeli sites had higher rates of occlusion with aprotinin than at US sites (European sites, 11.6\%; US sites, 4.4\%; Table V, columns 3 and 4). Similarly, saphenous vein grafts placed during the initial tercile of the study had higher rates of occlusion (initial tercile: 9.8\%; later terciles: 6.0\%; Table V, columns 3 and 4). The observed univariate (unadjusted) risk ratio for graft occlusion with aprotinin versus placebo treatment was greater for most patient subgroups of the Danish and Israeli patients compared with the ratios in the US patients (Table V, columns 5, 6, and 7).

The 3 European sites had a significantly higher proportion of patients with adverse graft and distal vessel features, which were associated with a higher proportion of graft occlusion in aprotinin-treated patients than in placebo-treated patients. When the risk ratio for graft occlusion by aprotinin versus placebo was adjusted by stepwise logistic regression analysis for all predictors of graft occlusion in both US and European patients, the predictive power of each variable was attenuated (Table V, column 8; Fig 1). The adjusted risk ratio for vein graft occlusion at Danish and Israeli sites was 1.7 versus 0.7 for US sites (Table V, column 8) and for the overall study the adjusted risk ratio was 1.1 . The adjusted confidence intervals for risk of graft occlusion with aprotinin treatment versus placebo treatment remained above 1.0 for female gender, for distal vessels of poor quality, and for distal vessel sizes below 1.5 mm (Table V, column 9; Fig 1). Fig 2 summarizes the effect of aprotinin versus placebo treatment on risk ratios after adjustment for selected important variables.

Bifurcation or sequential vein grafts were used in $31 \%$ of patients at US sites compared with $15 \%$ at Danish and Israeli sites $(P=.001)$. Covariate analysis 
Table IV. Analysis of graft occlusion

\begin{tabular}{|c|c|c|c|c|c|c|}
\hline & Aprotinin & Placebo & $\begin{array}{l}A-P \text { difference } \\
(C I)\end{array}$ & $\begin{array}{l}\text { Risk ratio for } \\
\text { occlusion }(A / P)\end{array}$ & $90 \% C I$ & $\mathrm{P}$ value \\
\hline \multicolumn{7}{|l|}{$\begin{array}{l}\text { Patients with any occluded SVG } \\
\text { (aprotinin; placebo) }\end{array}$} \\
\hline \multicolumn{7}{|l|}{ All sites } \\
\hline All patients $(363 ; 340)$ & 15.4 & 10.9 & $4.5(1.3 ; 9.6)$ & 1.5 & $1.1-2.1$ & .03 \\
\hline \multicolumn{7}{|l|}{ US sites } \\
\hline All patients $(202 ; 179)$ & 9.4 & 9.5 & $-0.1(-3.8 ; 5.9)$ & 1.0 & $0.5-1.8$ & .72 \\
\hline Surgery in first entry tercile $(64 ; 66)$ & 7.8 & 12.1 & $-4.3(-13.7 ; 7.0)$ & 0.6 & $0-1.7$ & .60 \\
\hline Surgery in second/third entry tercile $(138 ; 113)$ & 10.1 & 8.0 & $2.1(-2.8 ; 10.1)$ & 1.3 & $0.6-2.6$ & .35 \\
\hline \multicolumn{7}{|l|}{ Israeli and Danish sites } \\
\hline All patients $(161 ; 161)$ & 23.0 & 12.4 & $10.6(3.4 ; 17.3)$ & 2.1 & $1.3-2.9$ & .01 \\
\hline Surgery in first entry tercile $(55 ; 51)$ & 34.5 & 15.7 & $18.8(10.6 ; 35.3)$ & 2.8 & 2.1-6.4 & .002 \\
\hline Surgery in second/third entry tercile $(106 ; 110)$ & 17.0 & 10.9 & $6.1(-2.5 ; 13.6)$ & 1.7 & $0.8-2.6$ & .25 \\
\hline \multicolumn{7}{|l|}{ Occluded distal SVG insertions (aprotinin; placebo) } \\
\hline \multicolumn{7}{|l|}{ All sites } \\
\hline All SVG insertions (897; 837) & 7.5 & 4.8 & $2.7(0.9 ; 4.8)$ & 1.7 & $1.2-2.1$ & .02 \\
\hline Single SVG $(677 ; 656)$ & 9.2 & 5.9 & $3.3(0.7 ; 5.6)$ & 1.6 & $1.1-2.1$ & .03 \\
\hline Sequential SVG $(220 ; 181)$ & 2.3 & 0.6 & $1.7(-1.2 ; 3.0)$ & 4.2 & $0.0-5.8$ & .49 \\
\hline \multirow{2}{*}{\multicolumn{7}{|c|}{$\begin{array}{l}\text { Patients with occluded ITA grafts } \\
\text { (single grafts only, aprotinin; placebo) } \\
\text { All sites }\end{array}$}} \\
\hline & & & & & & \\
\hline All patients $(326 ; 304)$ & 1.8 & 1.0 & $0.8(-0.7 ; 2.7)$ & 1.9 & $0.3-3.8$ & .32 \\
\hline
\end{tabular}

Confidence interval (CI) is conditional on observed placebo rate. A, Aprotinin; $P$, placebo; SVG, saphenous vein graft; ITA, internal thoracic artery.

revealed that these grafts were less likely to occlude than single grafts, regardless of treatment group. The distal insertions of bifurcation or sequential grafts were 4 times less likely to occlude than single insertion vein grafts in aprotinin-treated subjects and 9 times less likely to occlude in placebo-treated patients (Table V, columns 3 and 4).

Lower protamine doses were independently associated with a greater likelihood of graft occlusion and also with a greater adverse effect of aprotinin on graft patency (Table V). The total protamine dose was highly correlated with the total heparin dose. This reflects the use of the heparin-protamine titration test results obtained at the end of $\mathrm{CPB}$ to determine protamine dosing. The lower mean protamine dose in the Danish and Israeli patients, despite higher mean heparin doses associated with this patient population (Table I), may reflect a longer duration of procedure, relative heparin resistance caused by greater preoperative use in unstable patients, lower levels of circulating heparin at the end of bypass, or other indeterminate factors.

Regression analysis found no relation between saphenous vein graft occlusion and the extent of blood loss or replacement. In addition, we modeled risk for saphenous vein graft occlusion using predictors of graft occlusion and found that the hemostatic benefit of aprotinin in reducing blood loss and the need for blood product replacement was independent of the probability for graft occlusion.
Clinical events. Six hospital deaths were observed in the aprotinin group (1.4\%), whereas 7 hospital deaths occurred in the placebo group (1.6\%). Serious adverse events (including those leading to death) occurred in $18 \%$ of aprotinin-treated patients (77/436) and $17 \%$ of placebo-treated patients (73/434) and were almost entirely cardiorespiratory in origin. The prevalence of serious bleeding was $1 \%$ in aprotinin-treated patients (5/436) compared with 5\% in placebo-treated patients (22/434; $P=.001)$.

No statistically significant differences were noted between the 2 treatment groups in the prevalence of definite, probable, or possible myocardial infarctions based on blinded readings from the core ECG laboratory (aprotinin: 2.9\%; placebo: 3.8\%; Table VI). Eightyeight percent of patients in both the aprotinin and placebo groups had no evidence of myocardial infarction. Of the 668 patients with both ECG and angiographic data available, $40 \%$ of the 55 patients with a definite or probable myocardial infarction had an occluded saphenous vein graft; however, in these patients, there was no significant difference in occlusion rates between the aprotinin-treated and placebo-treated patients $(P=.50$; Table VI). Of these same 668 patients, $24 \%$ of 90 patients with 1 occluded graft or more had an infarction, but again, there was no significant difference in infarction rates between the aprotinin and placebo groups $(P$ $=.34$, Table VI). Logistic regression analyses showed no interaction of treatment with patient subgroups and 
Table V. Analysis of the interaction between variables predictive of saphenous vein graft occlusion and the effect of aprotinin versus placebo on graft occlusion

\begin{tabular}{|c|c|c|c|c|c|c|c|c|}
\hline \multirow{3}{*}{$\begin{array}{l}\text { Variables predictive of } \\
\text { SVG occlusion } \\
\text { (No. of grafts) }\end{array}$} & \multirow{3}{*}{$\begin{array}{l}\text { P value: } \\
\text { drug-by-covariate } \\
\text { interaction }\end{array}$} & \multirow{2}{*}{\multicolumn{2}{|c|}{$\begin{array}{c}\text { Observed } \\
\text { occlusion rates }(\%)\end{array}$}} & \multicolumn{5}{|c|}{ Risk ratio for occlusion (aprotinin versus placebo) } \\
\hline & & & & \multicolumn{3}{|c|}{ Observed } & \multicolumn{2}{|c|}{$\begin{array}{c}\begin{array}{c}\text { Adjusted for all } \\
\text { predictive variables }\end{array} \\
\text { All patients }\end{array}$} \\
\hline & & Aprotinin & Placebo & All patients & US patients & $\begin{array}{c}\text { Danish and } \\
\text { Israeli patients }\end{array}$ & Risk ratio & $90 \% \mathrm{Cl}$ \\
\hline [1] & [2] & [3] & [4] & [5] & {$[6]$} & [7] & [8] & [9] \\
\hline Site location & NS & & & & & & & \\
\hline All sites (1734) & & 7.5 & 4.8 & 1.7 & 1.1 & 2.1 & 1.1 & $0.6-1.8$ \\
\hline US sites (990) & & 4.4 & 4.0 & NA & 1.1 & NA & 0.7 & $0.4-1.3$ \\
\hline Danish and Israeli sites (744 & & 11.6 & 5.8 & NA & NA & 2.1 & 1.7 & $0.9-3.0$ \\
\hline Enrollment tercile & NA & & & & & & & \\
\hline First (594) & & 9.8 & 5.5 & 1.9 & 1.0 & 2.3 & 1.2 & $0.7-2.0$ \\
\hline Second/third (1140) & & 6.0 & 4.0 & 1.6 & 1.4 & 1.9 & 1.0 & $0.6-1.8$ \\
\hline Gender & .06 & & & & & & & \\
\hline Female (187) & & 20.7 & 4.2 & 5.9 & * & 6.1 & 5.3 & $1.8-15.8$ \\
\hline Male (1547) & & 5.7 & 4.6 & 1.3 & 1.0 & 1.6 & 0.9 & $0.5-1.5$ \\
\hline Age & .07 & & & & & & & \\
\hline$>62$ y $(841)$ & & 8.4 & 3.8 & 2.3 & 1.4 & 2.3 & 1.6 & $0.8-3.1$ \\
\hline$\leq 62$ y $(887)$ & & 6.7 & 4.9 & 1.4 & 1.2 & 2.0 & 0.7 & $0.4-1.3$ \\
\hline LVEF & .06 & & & & & & & \\
\hline$\geq 0.50(1201)$ & & 6.9 & 5.0 & 1.4 & 1.2 & 1.5 & 0.8 & $0.5-1.5$ \\
\hline$<0.50(523)$ & & 8.1 & 3.4 & 2.5 & 1.4 & 4.2 & 1.8 & $0.8-4.5$ \\
\hline ASA $\leq 2 \mathrm{~d}$ of operation & .05 & & & & & & & \\
\hline Yes (628) & & 5.0 & 1.8 & 1.1 & 1.1 & 1.1 & 0.6 & $0.3-1.6$ \\
\hline No (1106) & & 8.5 & 4.4 & 2.0 & 1.3 & 2.8 & 1.4 & $0.8-2.5$ \\
\hline Graft type & NA & & & & & & & \\
\hline Single (1333) & & 8.9 & 5.6 & 1.6 & 1.1 & 2.0 & 1.1 & $0.7-2.0$ \\
\hline Y or sequential (401) & & 2.3 & 0.6 & 4.2 & 3.0 & $\dagger$ & 0.8 & $0.5-1.4$ \\
\hline Distal vessel size & .06 & & & & & & & \\
\hline$\leq 1.5 \mathrm{~mm}(976)$ & & 10.8 & 5.3 & 2.2 & 1.7 & 2.5 & 1.9 & $1.2-3.2$ \\
\hline$>1.5 \mathrm{~mm}(752)$ & & 2.4 & 3.5 & 0.7 & 0.3 & 1.1 & 0.5 & $0.2-1.2$ \\
\hline Distal vessel quality & .08 & & & & & & & \\
\hline Fair/poor (938) & & 11.4 & 5.5 & 2.2 & 1.8 & 2.6 & 1.9 & $1.1-3.3$ \\
\hline Good (787) & & 2.3 & 3.4 & 0.7 & 0.6 & 0.7 & 0.5 & $0.3-1.1$ \\
\hline Graft size & .09 & & & & & & & \\
\hline Small/medium (1463) & & 7.5 & 4.5 & 1.7 & 1.4 & 2.1 & 1.2 & $0.7-2.2$ \\
\hline Large (254) & & 5.9 & 4.5 & 1.3 & 0.0 & 2.3 & 0.5 & $0.2-1.2$ \\
\hline Total protamine dose & .07 & & & & & & & \\
\hline$<$ Mean = 342 mg (914) & & 10.6 & 5.5 & 2.0 & 3.3 & 1.9 & 1.8 & $0.8-3.7$ \\
\hline$>$ Mean $=342 \mathrm{mg}(820)$ & & 5.4 & 4.0 & 1.4 & 0.9 & 2.3 & 0.6 & $0.3-1.1$ \\
\hline
\end{tabular}

$N A$, Not applicable. For column 2, NA indicates that the interaction was not selected for inclusion in the statistical model $(P<.15) . S V G$, Saphenous vein graft; $L V E F$, left ventricular ejection fraction; $A S A$, acetylsalicylic acid (aspirin).

*Risk ratio is infinite because no placebo events exist; aprotinin occlusion rate $=8.3 \%$.

$\dagger$ Risk ratio is infinite because no placebo events exist; aprotinin occlusion rate $=1.9 \%$.

no overall effect of treatment on perioperative definite or probable myocardial infarction rates.

\section{Discussion}

When administered to patients undergoing CPB surgery, aprotinin is consistently associated with decreased fibrinolysis and reduced bleeding in the perioperative period. However, reduction in fibrinolysis could potentially increase the risk of thrombus formation and perioperative myocardial infarction. This doubleblinded, randomized study was undertaken in a sufficiently large number of subjects, using blinded readings at a core laboratory, and applying uniform entry and interpretation criteria to evaluate the safety of aprotinin in terms of its effect on graft patency. Secondary analyses of differences among clinical site procedures and 


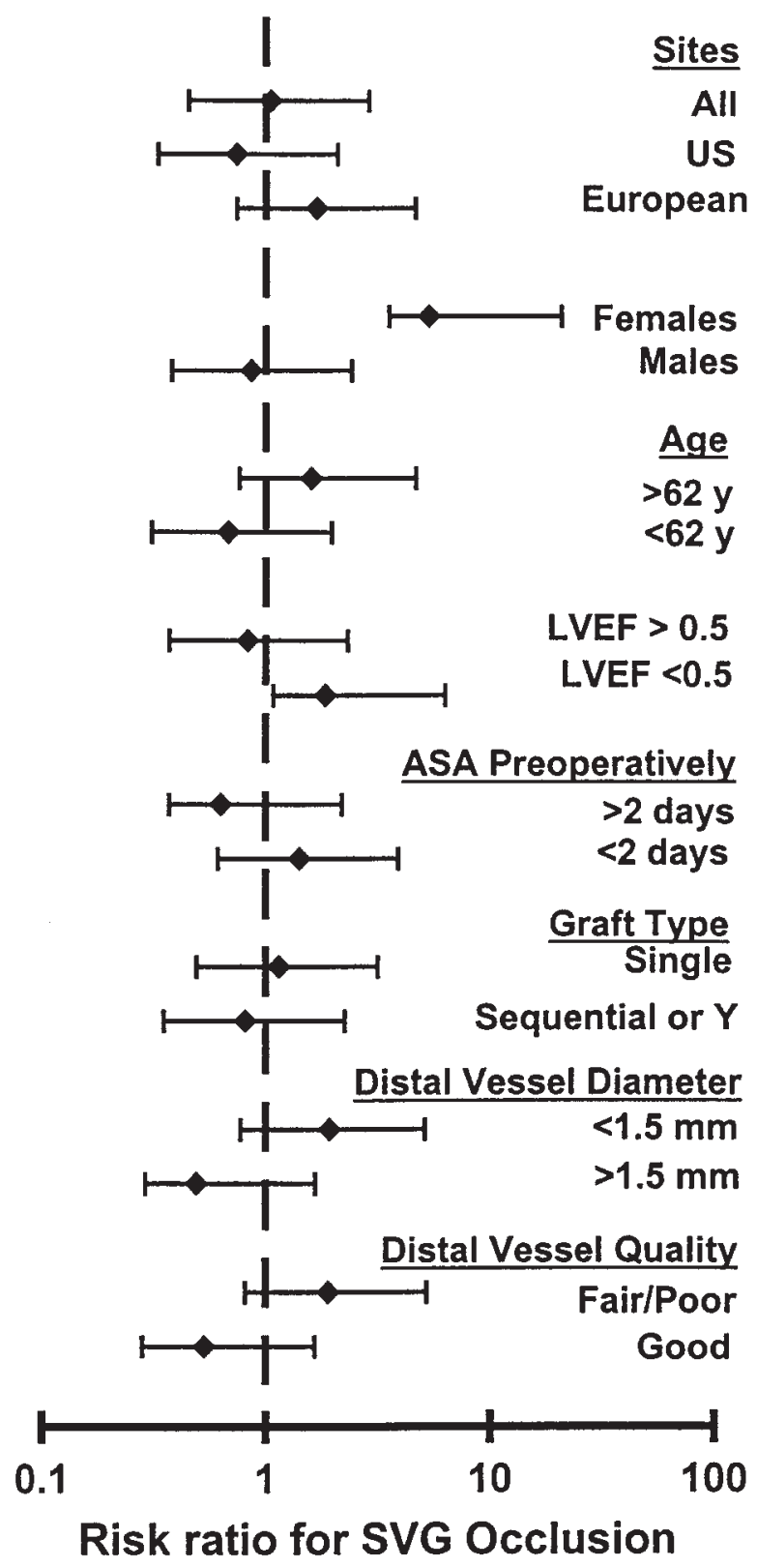

Fig 1. The effects of aprotinin compared with placebo treatment after adjustment for clinical, surgical, and angiographic variables are shown as risk ratios (diamonds) and $90 \%$ confidence intervals (horizontal lines) for saphenous vein graft occlusion. A log scale is used. Selected variables shown in Table $\mathrm{V}$ are plotted. A ratio greater than 1.0 denotes a higher risk for graft occlusion with aprotinin than with placebo treatment. $L V E F$, Left ventricular ejection volume; $A S A$, acetylsalicylic acid (aspirin); $S V G$, saphenous vein graft.

patient and graft characteristics revealed important considerations when aprotinin is administered.

Blood loss and blood product replacement. This study confirms the efficacy of a high-dose aprotinin regimen in reducing both blood loss and the requirement for allogeneic blood transfusion. Aprotinin elicited a significant reduction in the total thoracic drainage volume, the magnitude of which was comparable with that reported previously by Lemmer and colleagues. ${ }^{8,9}$ Aprotinin decreased the need for allogeneic RBC transfusions and reduced the total donor exposures per patient to fresh frozen plasma and cryoprecipitate. The present study demonstrated a $40 \%$ transfusion rate for aprotinin-treated patients versus a 58\% rate for placebo-treated patients. This finding is consistent with earlier reports showing that $34 \%$ to $38 \%$ of aprotinin recipients versus $52 \%$ to $55 \%$ of placebo recipients required blood transfusions. ${ }^{8,9}$ Moreover, aprotinin treatment was associated with a $47 \%$ reduction in reoperation for bleeding (11 vs 19 patients).

Angiographic results: Influence of graft and recipient coronary vessel characteristics. Prior studies of early graft occlusion, generally conducted with smaller numbers of subjects and nondefinitive imaging methods, have shown no adverse effect of aprotinin on clinical events or graft patency. $3,8,11$ The overall results of this graft patency investigation found an increased probability of saphenous vein graft occlusion with aprotinin administration when analyzed on both perpatient and per-graft bases. However, secondary analyses revealed a significant interaction between certain patient, vessel, and graft characteristics that were predictive of graft occlusion in both aprotinin and placebo groups and associated with an adverse effect of aprotinin on graft patency. Multiple graft and recipient coronary vessel characteristics are known to affect saphenous vein graft patency, including the quality of the vein (varicosities, thickened wall) and the small size (especially $<1.5 \mathrm{~mm}$ in diameter) and poor quality of the recipient vessels. ${ }^{16-22}$

The occlusion rate with aprotinin treatment for vein grafts to vessels less than $1.5 \mathrm{~mm}$ in diameter was $10.8 \%$ in this study, which compares favorably with the $17.9 \%$ occlusion rate previously observed in non-aprotinintreated patients 8 to 28 days after the operation. ${ }^{16}$ This comparison of vein graft occlusion is based primarily on grafts to the circumflex and right coronary vessels because vein grafts comprise only $10 \%$ of grafts to the anterior descending artery. Similarly, the $11.4 \%$ occlusion rate in vessels of poor quality with aprotinin use compares favorably with the occlusion rates of vein grafts to the right and circumflex coronary arteries-27.6\% for poor-quality and $15.4 \%$ for good-quality distal vessels, as previously reported by Paz and associates. ${ }^{16}$

These adverse graft and distal vessel characteristics were more prevalent in patients enrolled at the Danish and Israeli sites than in those enrolled at the US sites 


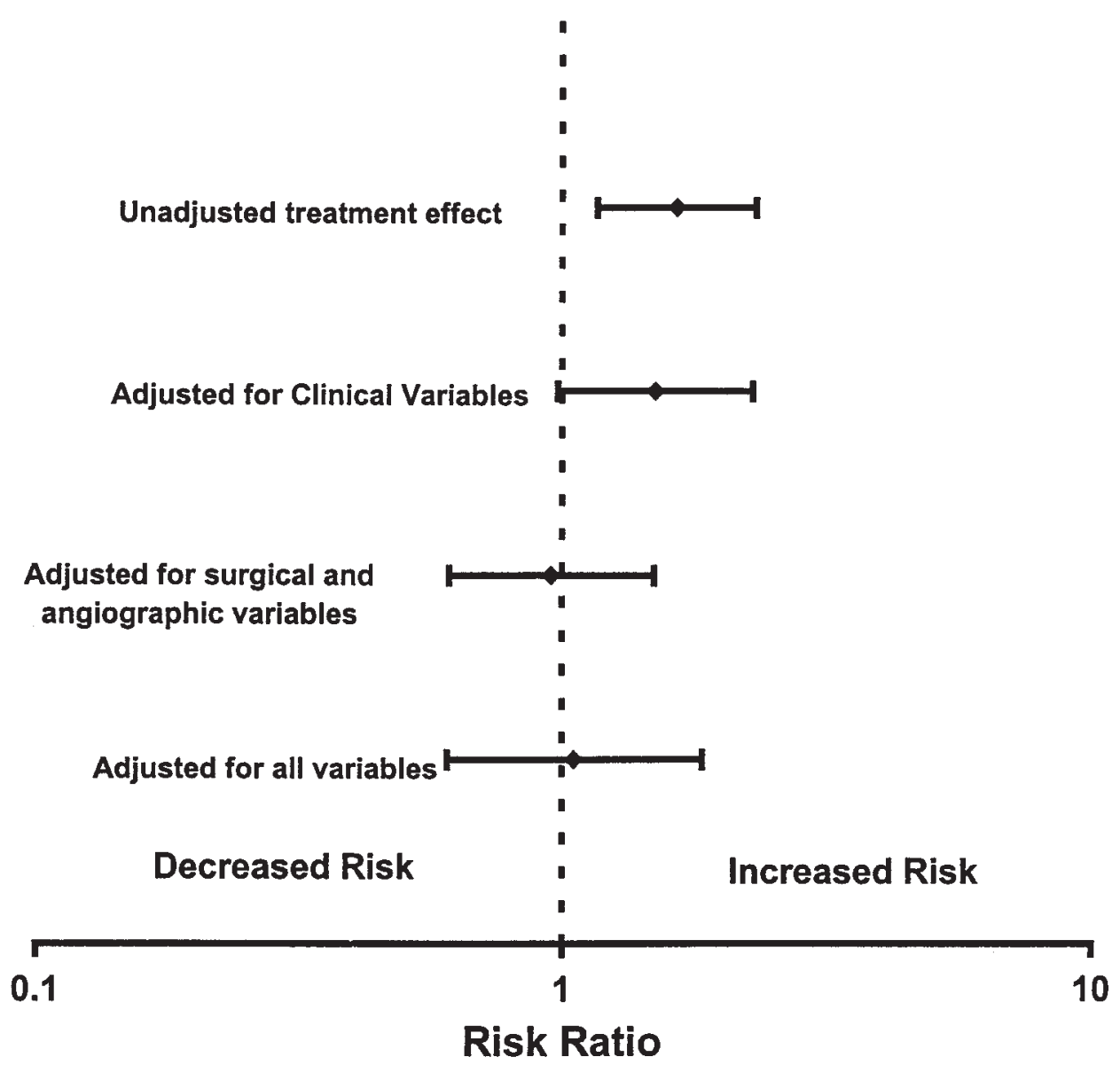

Fig 2. The effects of aprotinin compared with placebo treatment before and after adjustment with logistic regression model are shown as risk ratios (diamonds) and $90 \%$ confidence intervals (horizontal lines) for saphenous vein graft occlusion. A log scale is used. Clinical variables include age, gender, clinical site, tercile of study entry date, and aspirin use before the operation. Surgical and angiographic variables include left ventricular ejection fraction, graft type and size, distal vessel quality and size, and total protamine dose. A ratio greater than 1.0 denotes a higher risk for graft occlusion with aprotinin than with placebo treatment.

Table VI. Prevalence of myocardial infarction in aprotinin- and placebo-treated patients

\begin{tabular}{|c|c|c|c|c|c|}
\hline & \multicolumn{2}{|c|}{ Aprotinin patients } & \multicolumn{2}{|c|}{ Placebo patients } & \multirow[b]{2}{*}{$\mathrm{P}$ value } \\
\hline & Assessable & No. $(\%)$ & Assessable & No. $(\%)$ & \\
\hline \multicolumn{6}{|l|}{ MI* } \\
\hline Definite MI & 410 & $12(2.9)$ & 421 & $16(3.8)$ & .47 \\
\hline Definite or probable MI & 407 & $35(8.6)$ & 418 & $38(9.1)$ & .77 \\
\hline Definite, probable, or possible MI & 408 & $50(12.3)$ & 418 & $50(12.0)$ & .93 \\
\hline \multicolumn{6}{|l|}{ Definite, probable, or possible MI } \\
\hline US sites & 222 & $22(9.9)$ & 227 & $31(13.7)$ & .20 \\
\hline Danish and Israeli sites & 186 & $28(15.1)$ & 191 & $19(10.0)$ & .13 \\
\hline \multicolumn{6}{|l|}{ Combined analysis of MI and graft occlusion } \\
\hline Patients with assessable SVGs and ECG data & 340 & & 328 & & \\
\hline Patients with an occluded SVG & 54 & & 36 & & \\
\hline Patients with an occluded SVG and an MI & & $11(20.0)$ & & $11(31.0)$ & .34 \\
\hline Patients with a definite or probable MI & 30 & & 25 & & \\
\hline Patients with an MI having an occluded SVG & & $11(37.0)$ & & $11(44.0)$ & .50 \\
\hline
\end{tabular}

$M I$, Myocardial infarction; $E C G$, electrocardiogram; $S V G$, saphenous vein graft.

* Myocardial infarction was diagnosed on the basis of an electrocardiogram and the cardiac enzyme profile. 
and account for the higher graft occlusion in both treatment groups (Table IV). The difference was much more prominent when comparing total graft occlusions for aprotinin-treated patients (aprotinin, European sites: 11.6\%; aprotinin, US sites: $4.4 \%$ ) than for placebotreated patients (placebo, European sites: 5.8\%; placebo, US sites: 4.0\%; Table V). One explanation for these differences may be that the Danish and Israeli patients had more advanced disease or a somewhat larger number of graft insertions per patient with a greater proportion inserted into smaller distal vessels.

Angiographic results: Influence of surgical techniques, aprotinin administration, and monitoring. The site-by-site analyses, entry tercile analyses, and procedure questionnaires suggested that differences in saphenous vein harvesting techniques, aprotinin administration, and heparin monitoring may have had an effect on graft occlusion. Saphenous vein grafts preserved with blood-containing solutions appeared more likely to occlude than vein grafts preserved with non-blood-containing colloid (aprotinin, 9.3\%; placebo, $4.8 \%$ ). At the Danish and Israeli sites, which all used blood-containing perfusate, a higher rate of vein graft occlusion was observed with aprotinin treatment than with the use of placebo (aprotinin, 11.6\%; placebo, 5.8\%). This effect was not observed at the single US site that also used blood-containing perfusate (aprotinin, 1.0\%; placebo, 1.1\%). However, the existence of a definitive relationship between the nature of the perfusate and the aprotinin effects on graft patency cannot be concluded because of the confounding statistical effect of study center.

Regardless of the surgical technique used for vein harvesting, endothelial disruption, denudation, and cellular dysfunction occur. ${ }^{23-27}$ Blood-containing solutions have been reported to enhance endothelial preservation when compared with normal saline solution, ${ }^{27}$ but they appear to be no better or worse than balanced salt solutions. ${ }^{22,28}$ It has been suggested that the interaction of platelet aggregates, leukocytes, and fibrin with damaged areas of endothelium, which have been found more commonly on the endothelium of veins prepared with blood, further worsens the endothelial injury. ${ }^{22,29,30}$ Because aprotinin preserves platelet function and has antifibrinolytic properties, blood-containing preservation solutions that also contain aprotinin could lead to higher early graft closure rates.

Anticoagulation achieved during cardiac operations is commonly assessed from clotting times, with additional heparin administered accordingly. However, aprotinin inhibits contact activation, such that, when the celite-based activated clotting time is used, an artifactually prolonged clotting time results. Therefore heparin administration based on celite clotting times may result in inadequate anticoagulation and consequent thrombotic complications in aprotinin-treated patients. To avoid such complications in this study, we measured heparin levels directly by protamine titration. At a few sites, the results of activated clotting time measurements obtained during aprotinin use may have influenced the amount of additional heparin administered during surgery, potentially adversely affecting graft patency rates in aprotinin-treated patients.

The earlier observations by Levy and colleagues, ${ }^{10}$ that significant differences in activated clotting times may be obtained despite similar heparin concentrations in aprotinin-treated patients, emphasizes the importance of consistency in heparin dosing among treatment groups when comparing the risk for graft occlusion in aprotinin- and placebo-treated patients. When anticoagulation practices were guided by both activated clotting times and heparin concentrations, and the latter were maintained at 2.7 units $/ \mathrm{mL}$ or more (direct measurement), no difference in the occurrence of perioperative myocardial infarction in aprotinin versus placebo recipients was observed.

Clinical events. Cosgrove and associates ${ }^{7}$ previously reported data that showed a $12.4 \%$ prevalence of myocardial infarction in 113 aprotinin-treated patients compared with a $7.1 \%$ prevalence in 56 placebo-treated patients undergoing a second CABG $(P=.298)$. Postmortem examinations in 7 of 13 deaths at unspecified intervals after the operation revealed thrombi in half of the vein grafts in 4 aprotinin-treated patients compared with none in 3 placebo-treated patients. In contrast, the results of the current study of 831 patients with assessable ECGs showed that aprotinin did not adversely influence the prevalence of myocardial infarction or mortality, irrespective of which definition for myocardial infarction was used.

In a more recent multicenter study of repeat surgery for elective myocardial revascularization, ${ }^{10}$ definite or probable myocardial infarction occurred in 20 of 70 patients (29\%) receiving high-dose aprotinin and in 19 of 65 control patients (29\%). In our study of primary coronary surgery, the occurrence of myocardial infarction according to the same core laboratory and ECG criteria was substantially lower, with an $8.6 \%$ infarction rate for aprotinin-treated patients and a $9.1 \%$ rate for placebo-treated patients. Additionally, we observed a definite myocardial infarction in only $3.8 \%$ of placebo-treated patients, whereas it was seen in $12 \%$ of the placebo-treated patients undergoing repeat $\mathrm{CABG} .{ }^{10}$

\section{Summary and conclusions}

This study documented that high-dose aprotinin, administered prophylactically to patients having primary 
CABG, reduced blood loss, donor blood requirement, and the need to re-explore to stop bleeding without any increased risk of mortality or myocardial infarction. Saphenous vein graft patency in the overall study population indicated a higher occlusion rate after aprotinin than placebo. In US patients, in contrast to the European patients, the occlusion rate was essentially the same for aprotinin and placebo. Secondary analyses confirmed that patient and anatomic characteristics known from previous studies to promote graft occlusion similarly were found to do so in this study. In the presence of such characteristics, aprotinin was associated with an increased rate of early vein graft occlusion. The use of aprotinin in patients having primary $\mathrm{CABG}$, in whom the primary distal target vessels are less than $1.5 \mathrm{~mm}$ in diameter or of poor quality, may adversely affect patency, which may be mitigated by sequential grafting. Moreover, blood-containing preservation solutions for saphenous vein harvest techniques should be collected from the patient before the administration of aprotinin. Nevertheless, the interaction between aprotinin and predictors of graft occlusion did not compromise the beneficial effect of aprotinin in reducing blood loss or transfusion requirements.

\section{REFERENCES}

1. Laskowski M Jr, Kato I. Protein inhibitors of proteinases. Annu Rev Biochem 1980;49:593-626.

2. Verstraete M. Clinical applications of inhibitors of fibrinolysis. Drugs 1985;29:236-42.

3. Havel M, Grabenwoger F, Schneider J, Laufer G, Wollenek G, Owen A, et al. Aprotinin does not decrease early graft patency after coronary artery bypass grafting despite reducing postoperative bleeding and use of donated blood. J Thorac Cardiovasc Surg 1994;107:807-10.

4. Royston D, Bidstrup BP, Taylor KM, Sapsford RN. Effect of aprotinin on need for blood transfusion after repeat open-heart surgery. Lancet 1987;2:1289-91.

5. Van Oeveren W, Jansen NJ, Bidstrup BP. Effects of aprotinin on hemostatic mechanisms during cardiopulmonary bypass. Ann Thorac Surg 1987;44:640-5.

6. Bidstrup BP, Royston D, Taylor KM, Sapsford RN. Reduction in blood loss and blood use after cardiopulmonary bypass with high-dose aprotinin (Trasylol). J Thorac Cardiovasc Surg 1989; 97:364-72.

7. Cosgrove DM, Heric B, Lytle BW, Taylor PC, Novoa R, Golding LA, et al. Aprotinin therapy for reoperative myocardial revascularization: a placebo-controlled study. Ann Thorac Surg 1992; 6:1031-6.

8. Lemmer J, Stanford W, Bonney S, Breen J, Chomka E, Eldredge $\mathrm{WJ}$, et al. Aprotinin for coronary bypass operations: efficacy, safety, and influence on early saphenous vein graft patency. J Thorac Cardiovasc Surg 1994;107:543-53.

9. Lemmer JH Jr, Dilling EW, Morton JR, Rich JR, Robicsek F, Bricker DL, et al. Aprotinin for primary coronary artery bypass grafting: a multicenter trial of three dose regimens. Ann Thorac Surg 1996;62:1659-68.

10. Levy JH, Pifarré R, Schaff HV, Horrow JC, Albus R, Spiess B, et al. A multicenter, double-blind, placebo-controlled trial of aprotinin for reducing blood loss and the requirement for donor-blood transfusion in patients undergoing repeat coronary artery bypass grafting. Circulation 1995;92:2236-44.

11. Bidstrup BP, Underwood SR, Sapsford RN, Streets E. Effects of aprotinin (Trasylol) on aorta-coronary bypass graft patency. J Thorac Cardiovasc Surg 1993;105:147-53.

12. Prineas RJ, Crow RS, Blackburn H. The Minnesota Code manual of electrocardiographic findings: standards and procedures for measurement and classification. Littleton [MA]: John Wright PSG; 1982. p. 1-229.

13. Rautaharju PM, Calhoun HP, Chaitman BR. Novacode serial ECG classification system for clinical trials in epidemiological studies. J Electrocardiol 1992;24:179-87.

14. Chaitman BR, Alderman EL, Sheffield LT, Tong T, Fisher L, Mock MB, et al. Use of survival analysis to determine the clinical significance of new $\mathrm{Q}$ waves after coronary bypass surgery. Circulation 1983;67:302-9.

15. Chaitman BR, Zhaou SH, Tamesis B, Rosen A, Terry AB, Zumbehl KM, et al. Methodology of serial ECG classification using an adaptation of the Novacode for $\mathrm{Q}$ wave myocardial infarction in the bypass angioplasty revascularization investigation (BARI). J Electrocardiol 1996;29:265-77.

16. Paz MA, Lupon J, Bosch X, Pomar JL, Sanz G, GESIC Study Group. Predictors of early saphenous vein aortocoronary bypass graft occlusion. Ann Thorac Surg 1993;56:1101-6.

17. Roth JA, Cukingnan RA, Brown BG, Gocka E, Carey JS. Factors influencing patency of saphenous vein grafts. Ann Thorac Surg 1979;28:176-83.

18. Björk VO, Ekestrom S, Henze A. Ivert T, Landou C. Early and late patency of aortocoronary vein grafts. Scand J Thorac Cardiovasc Surg 1981;15:11-21.

19. Crosby IK, Wellons HA, Taylor JG, Maffeo CJ, Beller GA, Muller WH. Critical analysis of the preoperative and operative predictors of aortocoronary bypass patency. Ann Surg 1981; 193:743-51.

20. Zingone B, Salvi A, Pappalardo A, et al. A reappraisal of the factors affecting early patency of aortocoronary saphenous vein bypass grafts: current experience with extensive revascularization employing sequential grafting techniques. G Ital Cardiol 1985; 15:24-32.

21. Goldman S, Copeland J, Moritz T, Henderson W, Zadira K, Ovitt $\mathrm{T}$, et al. Starting aspirin therapy after operation: effects on early graft patency. Circulation 1991; 84:520-6.

22. Catinella FP, Cunningham JN, Srungaram RK, Baumann FG, Nathan IM, Glassman EA, et al. The factors influencing early patency of coronary artery bypass vein grafts: correlation of angiographic and ultrastructural findings. $\mathrm{J}$ Thorac Cardiovasc Surg 1982;83:686-700.

23. Adcock OT Jr, Adcock GL, Wheeler RE, Gregory RT, Snyder SO $\mathrm{Jr}$, Gayle RG. Optimal techniques for harvesting and preparation of reversed autogenous vein grafts for use as arterial substitutes: a review. Surgery 1984;96:886-94.

24. Dries D, Mohammad SF, Woodward SF, Nelsen RM. The influence of harvesting technique on endothelial preservation in saphenous veins. J Surg Res 1992;52:219-25.

25. Adcock GD, Adcock OT Jr, Wheeler JR, et al. Arterialization of reversed autogenous vein grafts: quantitative light and electron 
microscopy of canine jugular vein grafts harvested and implanted by standard or improved techniques. J Vasc Surg 1987;6:283-95.

26. Barner HB, Fischer VW. Endothelial preservation in human saphenous veins harvested for coronary grafting. J Thorac Cardiovasc Surg 1990;100:148-9.

27. Hoover EL, Ross M, Fani K, et al. Biochemical and histopathologic comparison between blood and saline storage of canine veins. J Vasc Surg 1988;7:543-8.

28. Lawrie GM, Weilbacher DE, Henry PD. Endothelium-dependent relaxation in human saphenous vein grafts: effects of preparation and clinicopathologic correlations. J Thorac Cardiovasc Surg 1990;100:612-20.

29. Bush HL Jr, Jakubowski JA, Curl GR, Deykin D, Nabseth DC. The natural history of endothelial structure and function in arterialized vein grafts. J Vasc Surg 1986;3:204-15.

30. Ramos JR, Berger K, Mansfield PB, Sauvage LR. Histologic fate and endothelial changes of distended and nondistended vein grafts. Ann Surg 1976;183:205-28.

\section{Appendix: IMAGE investigators Clinical investigators (alphabetical)}

Robert A. Albus, MD

Fairfax Hospital

Cardiac Vascular and Thoracic Surgery

3301 Woodburn Rd

Annandale, VA 22003

Mark E. Comunale, MD

Beth Israel Hospital

Department of Anesthesia

330 Brookline Ave

Boston, MA 02115

Emery W. Dilling, MD

1010 W. 40th St

Austin, TX 78756

Charles B. Hantler, MD

University of Texas Health Science Center

7703 Floyd Curl Dr

San Antonio, TX 78284-7838

Jerrold H. Levy, MD

Emory University School of Medicine

Department of Anesthesiology

1364 Clifton Rd, NE

Atlanta, GA 30322

Jeremy R. Morton, MD

7 Bramhall St

Portland, ME 04105

Moshe Nile, MD

Beilinson Medical Center

Division of Cardiothoracic Surgery

Petach-Tivka, Israel

Gosta Pettersson, MD

University Hospital of Copenhagen

Blegdamsvej 9

DK-2100 Copenhagen, Denmark
Christian Rasmussen, MD

University Hospital of Copenhagen

Blegdamsvej 9

DK-2100 Copenhagen, Denmark

Jeff Rich, MD

Sentara Hospital

400 West Brambleton Ave

Norfolk, VA 23510

Hartzell Schaff, MD

Mayo Clinic

200 First St, SW

Rochester, MN 55905

Gulshan Sethi, MD

Department of Veterans Affairs

Medical Center and University of Arizona

Health Sciences Center

$3601 \mathrm{~S}$ 6th Ave

Tucson, AZ 85723

Jens Juel Thiis, MD

Department of Cardiothoracic Surgery

The Rigshospital

Copenhagen University Hospital

Blegdamsvej 9

DK-2100 Copenhagen, Denmark

G. Uretzky, MD

Carmel Medical Center

7 Michal St

Haifa, Israel

Bernardo Vidne, MD

Beilinson Medical Center

Division of Cardiothoracic Surgery

Petach-Tivka, Israel

Donald B. Williams, MD

Department of Cardiovascular Surgery

Mt Sinai Medical Center

Miami Beach, FL 33140

Howard Wittels, MD

Department of Anesthesia

Mt Sinai Medical Center

Suite 211

Miami Beach, FL 33140

\section{Core laboratory: Angiography}

Edwin Alderman, MD

Stanford University Medical Center

CVRC

300 Pasteur Dr

Stanford, CA 94305

Brooke Hollak, RN

Stanford University Medical Center

300 Pasteur Dr, Rm H2170

Stanford, CA 94305 


\section{Core laboratory: Electrocardiography}

Bernie Chaitman, MD

St Louis University Hospital

13th Floor, Bordley Towers

3635 Vista Ave

St Louis, MO 63110-0250

\section{Bayer statistician}

Andrea Nadel

Bayer Corporation

400 Morgan Ln

West Haven, CT 06516-4175

\section{Discussion}

Dr Stephen Westaby (Oxford, United Kingdom). There has been intense interest in the antifibrinolytic agent aprotinin since the description of its hemostatic effects in 1984. Perhaps my first comment should be that fibrinolysis is a necessary process to maintain blood vessel patency in the face of thrombin generation during any type of operation. In moderately hypothermic coronary surgery, the difference in blood loss between aprotinin use or nonuse is usually in the region of $250 \mathrm{~mL}$. This is well documented, and further studies are not necessary.

The continuing controversy is focused on the adverse effects of aprotinin and whether use of this agent should be extended from high-risk operations to routine CABG.

The question, does aprotinin promote graft occlusion, is a very important one. Most centers have anecdotal cases of thrombosis, but this is the first international multicenter trial designed specifically to address the graft occlusion issue definitively by graft angiography.

As is inevitable with ambitious multicenter projects, there were some problems with design and compliance of the study.

First, this is a historic study because it ended in 1996 and more than 2 years have been required to analyze the data. I would suggest that the coronary population is changing with a rise in interventional cardiology, and most patients now have progressively worse vessels.

I identified a number of problems. There were different methods of vein graft preparation from center to center, and in 1 case, in an Israeli site, this led to a change in study protocol. Was a cell salvage device used in any of these patients and did blood cardioplegic solution contain aprotinin?

The problems of compliance were interesting. Twenty percent did not go on to graft angiography. Could you say how many of those sites were US, Danish, or Israeli?

Much of the data subanalysis was based on inexact science, because distal vessel size is underestimated when flow is restricted, and of course when the grafts were blocked and there was a proximal anastomosis, flow was restricted. The data were analyzed by the interested pharmaceutical company. Did the findings, as opposed to the study design, direct the type of analysis used?

I looked carefully at the difference between the sites. In the US, there were 10 sites with a mean number of patients of 47 . The range was 2 to 95 patients, which means that at least in 1 center only 1 patient was randomized each year. I think if you have a national CABG rate of more than 1000 per year, and most of the patients are men, and you select the patients for a trial like this, the graft occlusion rates are bound to be low.

In contrast, the 3 non-European centers randomized at least 133 patients each, there was a lower intervention rate in Europe, and more were female patients. This gave a difference in occlusion rates of 23 to 12 , which I think is very significant. Subanalysis of graft occlusion rates shows that aprotinin definitely promotes graft occlusion in women, who had a 5-fold increase over placebo, as well as in smaller vessels and those with distal poor vessels.

My impression from a European perspective is that now virtually every patient left over by the interventional cardiologist has 1 or more of the high-risk variables. In very few patients are all the coronary arteries larger than $1.5 \mathrm{~mm}$ or free from distal disease, and certainly most patients referred for coronary reoperation have the adverse characteristics that tend to promote graft occlusion with aprotinin.

The most important question about this study is whether the use of aprotinin is justified in CABG given the risks of graft occlusion documented by this study. Most patients will recover from a low hematocrit value without blood transfusion, but residual coronary occlusions leave the patient at risk from late ischemic events.

Dr Rich. With respect to the cell salvage device, it was not used during operations at my center. Blood cardioplegic solution would by default have aprotinin in it because we mix it as we proceed through the operation. I do not know what each center does with respect to the mixing of their blood cardioplegic solution, and these centers have not been asked that question specifically. We did not ask the question you raised about the use of aprotinin-containing blood for saphenous vein flushing, and it is reported in the manuscript.

I cannot tell you the percentage of patients who did not undergo angiography at the Danish and Israeli sites versus the others. Finally, with respect to the statistical analysis, the findings did not direct the type of analysis performed. It was predetermined and set before the onset of the trial. Dr Alderman at Stanford was very happy with the intent and design of the statistical analysis and had oversight with respect to it.

Mr Ben Bidstrup (Townsville, Australia). I think your group is to be congratulated for undertaking such a large study. It is often very difficult to get a cardiologist to look at our patients in the postoperative period, and I am sure patients who have an angioplasty and have a problem probably have multiple catheterizations, often in the first few weeks after their procedure.

This study highlights significant differences between the European and the US populations. This can be extrapolated to other countries in the world, such as Australia. Many of us outside of the US have waiting lists measuring months. The majority of our patients have been waiting for quite some time. They have many of those unfavorable characteristics that this study has identified. In a way, it is somewhat gratifying that the earlier studies such as the one which I presented a few years ago at this meeting and that of Dr Lemmer, 
which showed a slight trend toward increased graft occlusion in the saphenous veins, have been confirmed by the ultimate gold standard.

I have a couple of questions that I would like you to address. Was there any difference in the number of grafts placed on the patients between the US and the European sites? I wonder whether more grafts are placed to small vessels in the European groups, which may have made a difference in graft occlusion.

Perhaps you would speculate on another point. Our cardiologists who will do an angioplasty of the left anterior descending coronary artery and say, "I will lose the diagonal, but that won't matter very much; he'll have a little infarct and he won't have any angina." Would you look further at this patient population and see whether in the long-term there is going to be any difference in outcome, such as recurrence of symptoms or need for reoperation?

Dr Rich. I do not know the answer to the number of grafts, Europe versus US. My impression is that there was not a major difference. A follow-up study is already in progress; we have already evaluated patients who have been enrolled for 2 years for recurrence of angina, recurrence of event, reoperative rates, need for angioplasty, and treatment of angina with medical therapy. I have been very satisfied and will be happy to see all the other centers' results. It will be gratifying to show this to the cardiologists. We have literally no need for reoperation or interventional therapy. Among 72 patients, we have had 1 patient with angina and 4 late deaths, equally divided between aprotinin and placebo groups. My sense is that we are not having a lot of late problems with aprotinin, but the results verify that surgery is probably a good intervention for patients with coronary disease still.

Dr Randall B. Griepp (New York, NY). I am sorry. I have a problem with the analysis here. I can understand that there were more high-risk patients for graft occlusion in the European group than in the American group, and when you look at the distribution of patients, the difference in graft patency between the 2 geographical groups disappears. But with a prospective, randomized allocation of patients in the European as well as in the American group, the poor-risk patients for graft occlusion should have been distributed equally into aprotinin and placebo groups both in Europe and in the USA. How can you, then, with a post hoc analysis, go back and do away with the results that were built into the prospective experimental design? Perhaps you can explain.

Dr. Rich. I agree. One should not go through a study like this and then try to explain away the results. This can be done with virtually any study. However, we can evaluate the US patients and say there is no difference. If we then evaluate the European patients and see that there are differences, we then analyze the reasons for the differences and look for high risks. Fortunately, we can control for these high risks. If we then combine the data and do a risk stratification, the differences become insignificant. Therefore let us not deny the results that are there and see that there are anatomic and patient characteristics that really do promote graft occlusion, with or without aprotinin use, and use aprotinin in a logical way. 